\title{
OUTCOME AFTER TEMPORAL LOBECTOMY
}

Thirty seven patients, ages 7 to 18 years, who underwent temporal lobectomy for intractable seizures at the Mayo Clinic, Rochester, MN, between 1970 and 1983, were followed for a mean of 19 years (range 4 - 27 years). Mean age at seizure onset was $7.2 \mathrm{yrs}$ (range 1-16), and mean age at surgery was $14.4 \mathrm{yrs}$ (range 7-18). An excellent outcome (0-4 seizure frequency score based on Engel classification) was obtained in $31(88 \%)$ patients at 5 years, and in $19(60 \%)$ at 15 years. Of those followed at least 15 years, $40 \%(13 / 32)$ were seizure free at 5 years but had recurrence of seizures at 15-year follow-up; $9.5 \%(3 / 32)$ improved significantly; and $50 \%(16 / 32)$ were unchanged. Of 13 with long-term seizure recurrence ( 9 on medication), 6 had abnormal pathology including oligodendroglioma or ganglioglioma (4), ectopic neurons (1), and mesial temporal sclerosis in 1 . Of 19 patients who improved or did not relapse, only 2 had abnormal pathology (astrocytoma and arachnoid cyst) ( $\mathrm{p}=0.03)$. Long-term seizure recurrence was independent of a positive family history of epilepsy, history of head tauma, encephalitis, or febrile convulsions, or abnormal postoperative EEG. Only 3 of 32 followed were unemployed; 6 had no driver's license. (Jarrar RG, Buchhalter JR, Meyer FB, Sharbrough FW, Laws E. Long-term follow-up of temporal lobectomy in children. Neurology November (2 of 2) 2002;59:1635-1637). (Reprints: Dr Jeffery Buchhalter, Child and Adolescent Neurology, Mayo Clinic, 200 First Street SW, Rochester, MN 55905).

COMMENT. In this long-term study of children following temporal lobectomy for intractable seizures, of $88 \%$ with an initial excellent outcome by 5 years, half of the patients had recurrence of seizures by 15 years. The incidence of mesial temporal sclerosis in patients with long-term recurrence was only $2.7 \%$ in this series, compared to $14 \%$ in previous reported series. The poorer outcome with long-term follow-up should be considered in decisions to operate early in children with temporal lobe seizures.

The unpredictable nature of postoperative seizure relapse was stressed in a report of 282 temporal resections, mean age 26 years (range 4-59 years), from Kings College Hospital, London, UK (Hennessy MJ et al. Brain 2000;123:2445-2466; see Ped Neur Briefs 2001;15:5-6). The relapse rate was approximately $20 \%$, either immediately or after a 12 month seizure-free interval.

Previous studies of the natural history of recurrent seizures after resective surgery for epilepsy have shown that the outlook is better if seizure recurrence is delayed until after the first postoperative year. Also, changes in antiepileptic medication, dosages, or poor compliance may be important factors in recurrence of seizures. (see Wingkun EC, Awad IA et al. Epilepsia 1991; see Progress in Pediatric Neurology II, PNB Publishers, 1994;pp136-7).

\section{CAT SCRATCH DISEASE AND EPILEPSIA PARTIALIS CONTINUA}

An 18-year-old female young adult with seizures associated with cat scratch disease is reported from Norwalk Hospital, Yale University School of Medicine, CT. She presented with difficulties in speaking followed by generalized tonic-clonic seizures and continuous right facial motor seizures refractory to antiepileptic drugs. Audio-video EEG monitoring revealed the epilepsia partialis involving the right lower face and occasionally, the tongue and larynx, without surface EEG abnormalities. MRIs were initially normal, and later showed an increased signal on T2-weighted images in the left frontoparietal region. SPECT also showed a focus of increased activity in the same region. The patient had a new kitten at home and cat scratch disease (CSD) serology for Bartonella henselae was positive at a titer of 